\title{
Application of a BioBarrier to a mixed MTBE/ BTEX dissolved plume
}

\author{
C. L. Bruce and P. C. Johnson \\ Department of Civil and Environmental Engineering, Arizona State \\ University, United States of America
}

\begin{abstract}
A biological barrier was installed in a MTBE / BTEX plume at the Naval Base Ventura, Port Hueneme, California to demonstrate the effectiveness of four different barrier configurations on dissolved plume treatment. The barrier spans the $500-\mathrm{ft}$ wide plume, and is configured to illustrate the treatment potential of both in situ air sparging (IAS) alone as well as two variations of the enhanced MTBE bioremediation (EMB) in situ process on MTBE and mixed MTBE/BTEX dissolved plumes. Contaminant monitoring after three months of operation show MTBE concentration decreases of at least an order of magnitude in the most contaminated zone. BTEX concentrations are reduced by an order of magnitude in the MC- 100 seeded zone, while reductions in the SC-100 plot are slightly less after three months of treatment.
\end{abstract}

\section{Introduction}

Soil and groundwater contamination resulting from releases of anthropogenic chemicals has cost billions of dollars to locate and evaluate, and will cost hundreds of billions more to clean up. There are a number of techniques available to remediate contaminated soils and groundwater. These include physical containment, ex situ treatment, and in situ treatment by various forms of physical, chemical, and biological processes. Combinations of these processes are often more successful than individual techniques. In situ treatments are often less expensive due to the reduction of generated waste streams. One in situ biological treatment technique is the inoculation of the subsurface with a microbial population having specialized metabolic capabilities. This technique, coupled with an in situ sparging system, was applied to a dissolved plume 
originating from an automotive fuel release at a gasoline station. This gasoline contained the fuel oxygenate methyl tert-butyl ether (MTBE). MTBE is the most frequently added fuel oxygenate in the United States due to the ease of its production, its blending characteristics, its low cost and its high oxygen and energy content. Its solubility and low sorptive properties, coupled with its recalcitrance to degradation in the subsurface, lead to large plumes of MTBE from automotive fuel release sites.

\subsection{In situ air sparging (IAS)}

In situ air sparging is one of the most frequently applied treatment technologies to releases at gasoline stations in the United States. IAS is a treatment technology in which gas (usually air) is injected beneath the water table to promote remediation of contaminated soil and groundwater. The injected air or gas rises, due to buoyancy forces, in the form of channels or fingers through the aquifer from the point of injection (Figure 1). IAS takes advantage of physical and biological mechanisms to support restoration. Physically, volatile and semi-volatile contaminants partition into the fingers of air, where they are then transported to the vadose zone. Biologically, the growth of native organisms is stimulated by the addition of oxygen (a limiting nutrient in most subsurface communities), increasing the biotransformation rate of many organic chemicals.

IAS applications are often used in conjunction with soil vapor extraction systems in order to minimize off-site migration of hazardous chemical vapors. There are risks associated with the use of IAS, however, including enhanced migration of contaminated groundwater and vapors and the mobilization of previously stationary immiscible-phase materials.

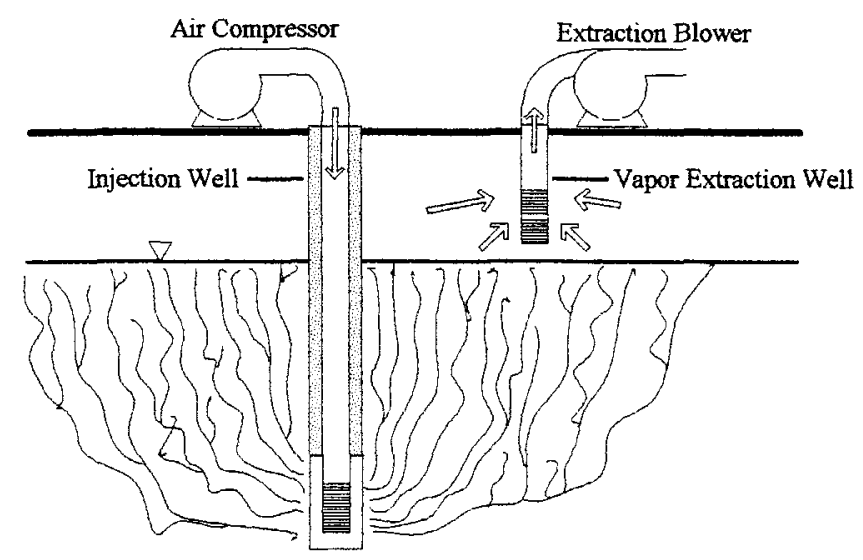

Figure 1. Typical in situ air sparging configuration 


\subsection{Enhanced MTBE bioremediation (EMB) in situ process}

The EMB process is a biological augmentation procedure coupled with an oxygen or air sparging system. Two cultures, isolated at Equilon Enterprises, LLC., were used in this study: SC-100, a pure culture, and MC-100, a mixed culture. Both cultures are aerobic MTBE degraders, capable of removing MTBE to concentrations of 0-5 ug-MTBE/L-water (Salanitro et al., 1999).

\subsection{Application site}

Port Hueneme is located in Ventura County, California, on the coast about 65 miles north of Los Angeles. The port was constructed in 1942 to serve as a secondary port to San Pedro (the major deepwater port for Southern CA) in Los Angeles during WWII. It currently houses the United States Naval Construction Battalion Center (USN CBC) which is a school for training civil engineers of the U. S. Navy and Air Force.

The plume of contamination originated from the Naval Exchange (NEX) Gasoline Station, which dispenses fuel and automotive maintenance services for employees of the base. Free product was discovered in the area around the NEX station in December of 1984. By March of 1985 the source was determined to be leaks in two of the fuel delivery lines running from the underground storage tanks (USTs) to the gas dispensers. Inventory records show that an estimated 10,800 gallons of leaded regular and premium unleaded gasoline were released between September 1984 and March 1985. It is unknown how much was spilled before that time.

Port Hueneme is situated on the Oxnard Plain and its near-surface lithology can be described as unconsolidated sands, silts, and clays, with minor amounts of gravel and fill. These sediments are fluvial-deltaic in origin. Based on borehole cuttings, the unconsolidated deposits are characterized into three units: an upper fine-grained silty sand unit (to 3-6 fbgs), an intermediate fine-to-coarse-grained sand unit (to $\sim 24 \mathrm{fbgs}$ ), and an underlying clay unit of gray sandy or silty clay.

\section{Installation}

In August 2000, an aeration/oxygenation system comprised of 252 direct-push wells was installed on the CBC parade ground, spanning the width of the MTBE and MTBE/BTEX plumes. The wells were installed at 2-ft intervals, with even wells extending $15-\mathrm{ft}$ bgs and odd wells extending 20 -ft bgs. 38 monitoring locations were installed upgradient of the barrier, 47 monitoring locations were installed downgradient of the barrier and 2 monitoring locations were established crossgradient. Each monitoring location is made up of $3 / 4$-in PVC wells terminating at 15 and $20-\mathrm{ft}$ bgs. Figure 2 illustrates the location of the monitoring and aeration wells used in this test demonstration. 
Injection of air and oxygen into the aquifer began in late September 2000, two months prior to culture injection, in order to sufficiently aerate the test zone. In December $2000,70-\mathrm{ft}$ sections of the oxygenated barrier were seeded with MC100 or SC-100 cultures. A further $10-\mathrm{ft}$ section was seeded with $\mathrm{SC}-100$ in a portion of the barrier that was only aerated, not oxygenated.

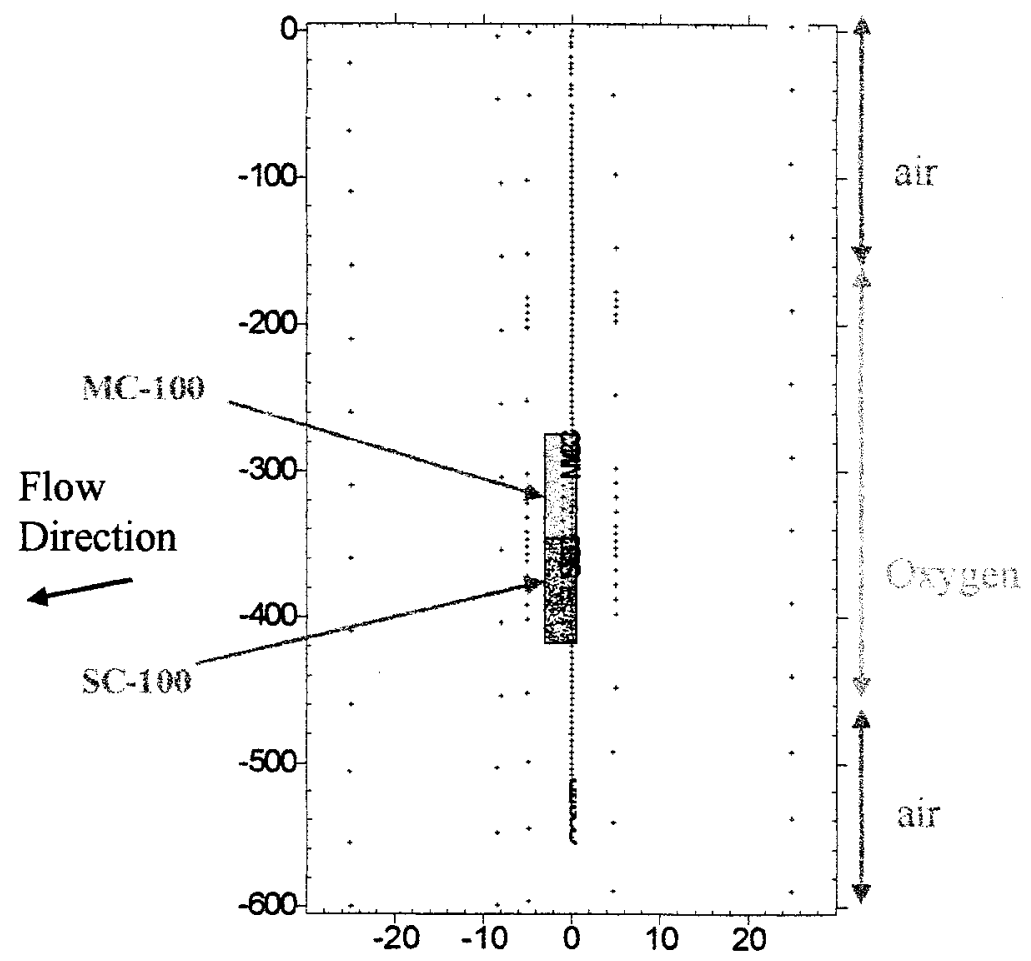

Figure 2. Monitoring well network and air/oxygen delivery system.

\section{Monitoring}

Concentrations of dissolved oxygen and contaminants were monitored twice before the air/oxygen delivery system was turned on. These concentrations were measured again before the seeding of the aquifer took place. The system will be monitored bimonthly until August of 2002. Figures 3 and 4 show the dissolved oxygen concentrations immediately downgradient of the air/oxygen delivery system from the beginning of the demonstration through the first three months. Figure 5 shows dissolved MTBE concentrations upgradient of the treatment barrier over the width of the plume. Figures 6 and 7 show dissolved MTBE concentrations immediately downgradient of the air/oxygen delivery system over 
the width of the plume. Figure 8 shows BTEX concentrations immediately downgradient of the biobarrier.

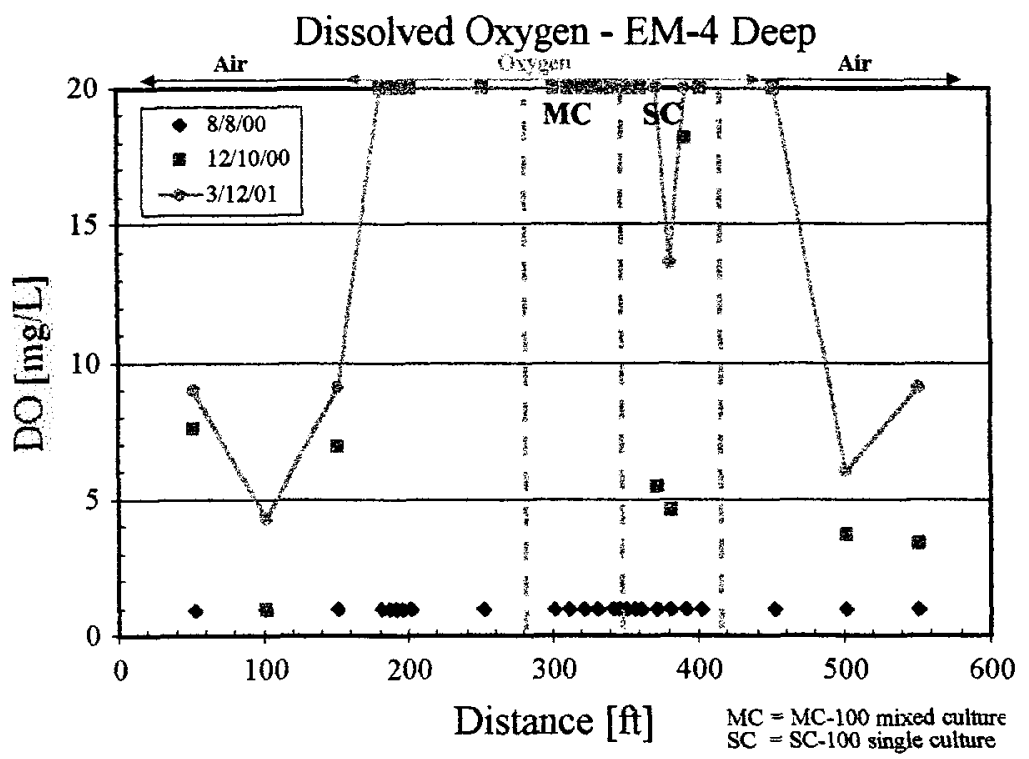

Figure 3. DO concentrations downgradient of the biobarrier in deep wells.

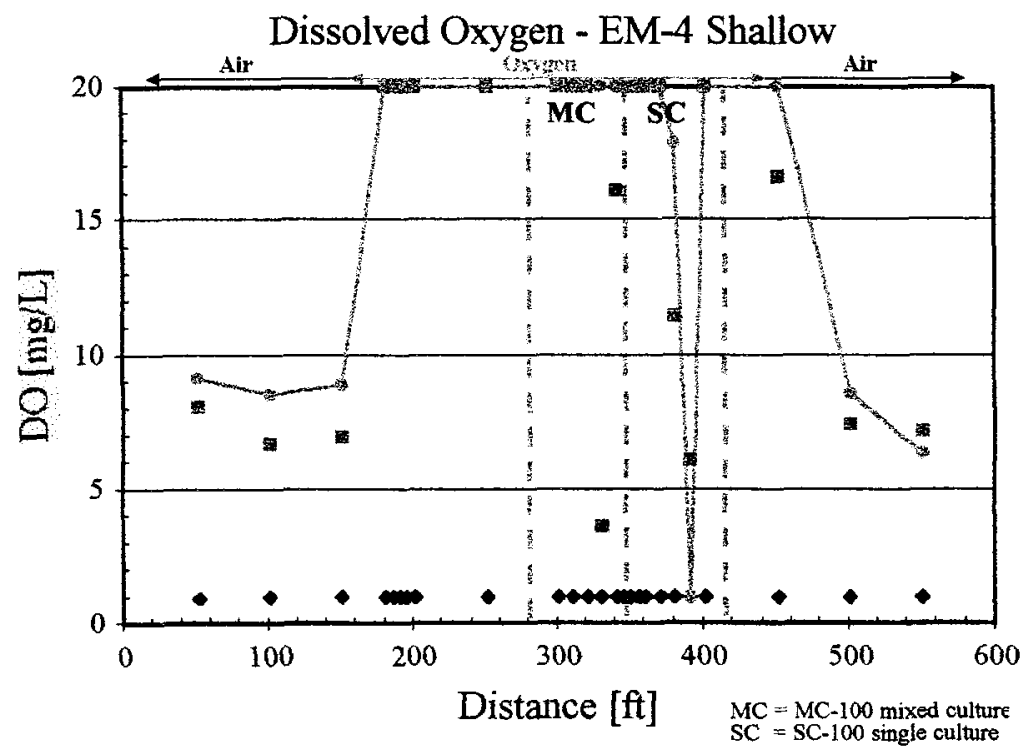

Figure 4. DO concentrations downgradient of the biobarrier in shallow wells. 


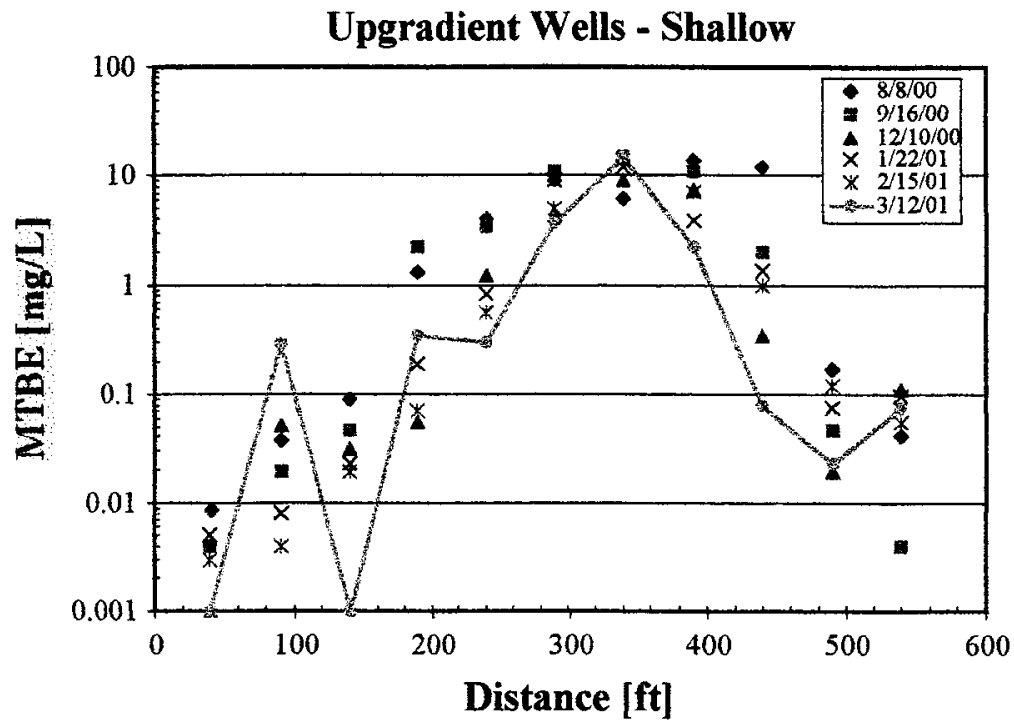

Figure 5. MTBE concentrations upgradient of the treatment barrier.

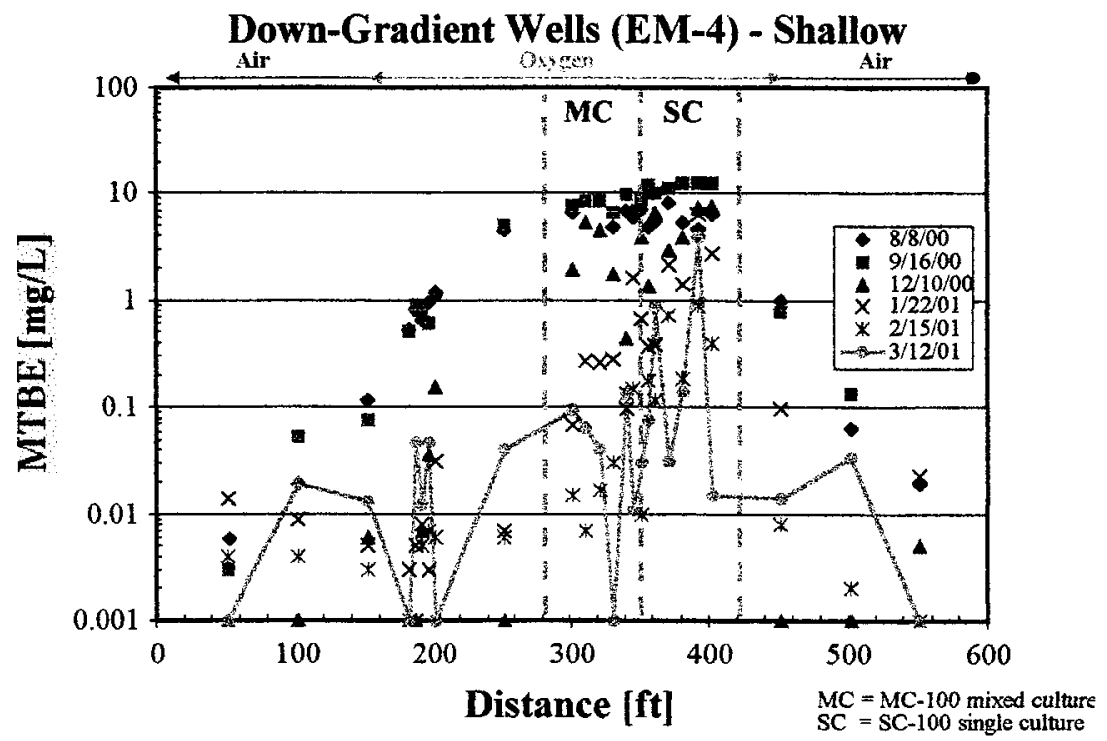

Figure 6. MTBE concentrations downgradient of the barrier in shallow wells. 


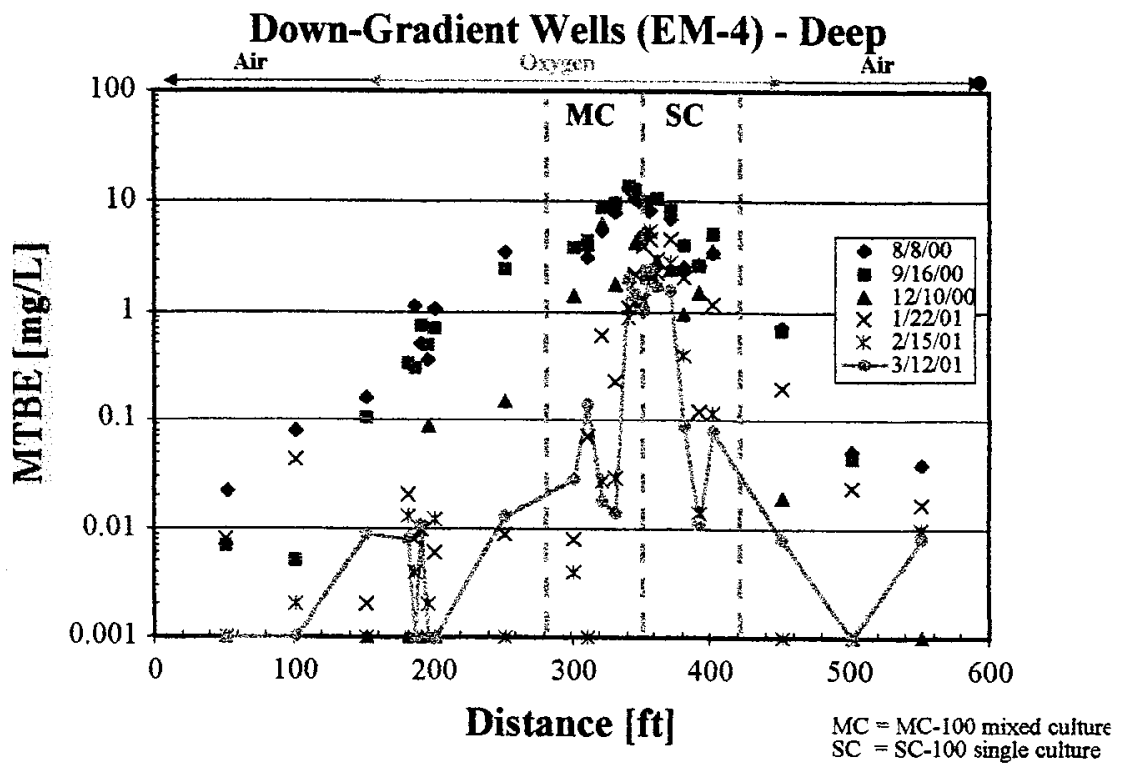

Figure 7. MTBE concentrations downgradient of the barrier in deep wells.

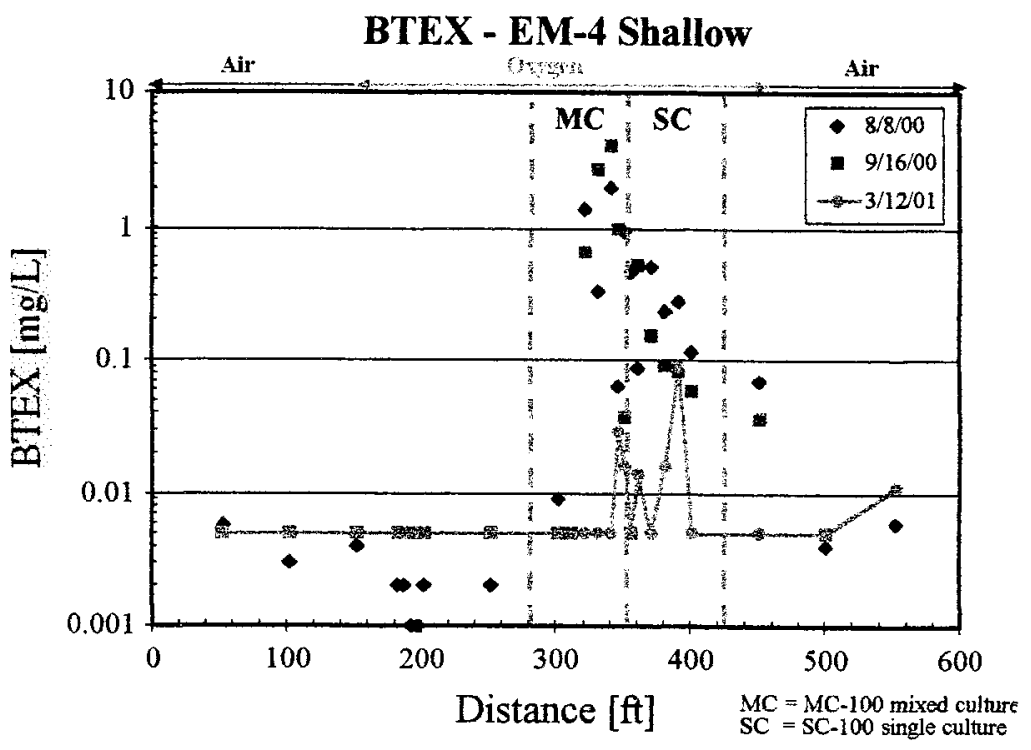

Figure 8. BTEX concentrations downgradient of the barrier in shallow wells. 


\section{Summary}

It appears that the BioBarrier air/oxygen delivery system is working as designed over the majority of the barrier. The zones which were seeded with MTBE-degrading organisms show concentration decreases of at least one order of magnitude in MTBE concentrations after 3 months of treatment. BTEX concentrations seem to respond more quickly to the mixed culture than the singleculture treatment. Further monitoring will show the capability and stability of this treatment technology. 